\title{
Ethical and Psychosocial Approach to Seniors
}

\section{E. Zacharova (Eva Zacharova), M. Magyaricsova (Monika Magyaricsova), L. Repiska (Libusa Repiska)}

Elizabeth University of Health and Social Work, Bratislava, Slovakia.

\section{E-mail address:}

eva.zacharova@seznam.cz

\section{Reprint address:}

Eva Zacharova

Elizabeth University of Health and Social Work, Bratislava, Slovakia.

Nam.1. maja 1

81102 Bratislava

Slovakia

Source: Clinical Social Work and Health Intervention

Volume: 11

Issue: 3

Pages: $80-84$

Cited references: 7

\section{Reviewers:}

Ivan Bartosovic

Elizabeth University of Health and Social Work, Bratislava, Slovakia

Selvaraj Subramanian

SAAaRMM, Kuala Lumpur

Malaysia

\section{Keywords:}

Ethics. Communication. Senior. Psychosocial Approach. Health Care Provider. Social Worker.

\section{Publisher:}

International Society of Applied Preventive Medicine i-gap

CSWHI 2020; 11(3): 80 - 84; DOI: 10.22359/cswhi_11_3_13 (C) Clinical Social Work and Health Intervention

\section{Abstract:}

\section{Introduction}

Aging is characteristic of every living organism and is an integral part of life. It concerns not only individuals, but is generalized to entire populations. It is thus becoming an important phenomenon in the life of modern society which in
Old age is an inevitable stage of human life, very often accompanied by bio-psycho-social changes in a person's personality. Health and social care professionals come into contact with seniors facing difficult life situations which they try to manage together. This article is focused on the area of ethical and psychosocial approaches in the care of seniors.

line with current demographic trends is becoming a highly debated area.

Our population is aging. Today, as a result of better living conditions, health care and other factors people are living longer than ever before. The aging of the population will continue and 
will mainly affect the population of seniors themselves as the fastest growing population group will be the oldest elderly people: i.e. 80 years and older. (3)

Demographic forecasts point to a clear trend in global population aging. This brings with it a number of problems in the field of health and social care. Life expectancy itself ceases to be the main parameter and the quality of life of a senior comes to the fore. The senior population as a whole represents a very heterogeneous group, which consists of sick and healthy individuals. The task nowadays is to be prepared for this fact and to participate in the creation of favorable conditions and circumstances for seniors.

Life expectancy will reach 85 to 90 years in the middle of the 21 st century. Seniors at this age will have depleted physiological reserve mechanisms such as immunity, adaptability, and decreased fitness. Future seniors will also have other demands on health, social and community services which will have to adapt to their needs.

Nursing care for seniors places high demands on expertise and ethical approaches. In order to provide quality professional and dignified care a health care professional must know the biological, psychological and social changes that take place in old age; have the right ethical and moral attitudes and characteristics such as the ability to empathize and communicate sensitively.

Kutnohorská states that speech and ethics are the most remarkable qualities that make a person different from everything else alive. It is very important for health professionals and social workers to be able to communicate properly with seniors. This is also an expression of an ethical approach and empathy for them. Communication should be: sensitive; tactful; helpful; empathetic with an interest in listening; adapted to their style and way of life; with an understandable amount of information; conducted decently and at a social level. (2)

The ethical aspects of care for seniors are based on the principle of the Hippocratic Oath „first, do no harm“ (primum non nocere). This principle is universal and still valid, it is concealed in all ethical principles of the 21 st century.

In 1991, the United Nations General Assembly (Resolution 46/91) already declared the basic ethical principles in the approach to seniors, which we should strive for today. It is about pre- serving the dignity and autonomy of seniors, or the need to maintain his/her control over what is happening, then self-realization, participation or belonging, benefit and security. The basis for ensuring the respect that seniors deserve is the fight against age discrimination and respect for the dignity of the elderly.

In addition to economic aspects, the ethical approach to seniors is influenced mainly by prejudices about old age and aging. Healthcare professionals and social workers are not immune to these facts and must therefore perceive their own views and values on aging. Among the most important ethical principles in the care of seniors in health and social care, but also in the social approach to seniors is dignity the content of which is above all respect and also the strengthening of self-esteem and autonomy. The right to decide for oneself comes to the fore here.

Demographic forecasts continue to indicate an increase in seniors with limited self-sufficiency or even so-called „fragile seniors“, who require a specific approach in the health and social spheres. In the future, therefore, the importance of the medical field caring for sick seniors, i.e. geriatric medicine, will increase. It places a crucial emphasis on an holistic approach to the senior patient, and not on just one, albeit seemingly main, diagnosis. Geriatric medicine strives to: maintain physical and mental activity for as long as possible; avert the loss of self-sufficiency; improve the prognosis of seniors in case of illness. The approach to geriatric multi-morbid patients as well as other seniors should include interdisciplinary cooperation in the medical, nursing and psychosocial spheres. Efforts in the field of psychological activity on seniors are beneficial only if it is based on:

- the paradigm of a physiological, healthy person;

- knowledge of the entire life history of a senior; - approach to the senior patient as a human personality;

- knowledge in relation to values, people, to oneself and the future.

It shows that maintaining high abilities until old age is always an expression of a strong integrated personality with a prospective focus. However, the fact remains that during the developmental curve of human life there are natural changes in cognitive abilities in a number of 
mental processes from: changes in sensory thresholds; perception; perceptual-motor coordination; memory functions to the highest intellectual performance. All these fundamentally affect their quality of life.

Quality of life, self-realization and interaction with the environment are often threatened values in old age, including: extreme cases of segregation; discrimination; loss of meaning in life; social deprivation; balancing on the edge of suicide.

Quality nursing care plays an important role, the essence of which is the intervention carried out by medical and psychological means in order to improve the life and health of seniors. Kalvach and Onderková state that it is ,the broadest professional interaction, a cultivated, professionally modulated approach of any medical or social worker." (1)

Psychological approach to seniors means above all a thoughtful approach where in their work the health care professional and social worker are able to take into account all the real contexts, including psychological and social. It means managing the contradictons between situations from the the view of a professional worker and from the view of the senior. Both the health care provider and the social worker must resist emotional and professional wear and tear, deformity and toughness that lead to a reduced view of the senior and their problems. Psychological help lies in the fact that health professionals and social workers create a psychosocial terrain for the patient on which unanimously action can be applied in an essential way.

The psychosocial approach to seniors should focus on:

- an professional and individual approach to the senior's personality based on a psychosocial history;

- respecting changes in mental functions during aging;

- choosing the appropriate form of communication to gain trust and create a favorable emotional climate;

- applying a non-directive approach, including the provision of truthful information, with the elimination of words that reinforce fear and anxiety;

- providing the possibility of physical presence and direct physical contact with family members and other close persons;
- compliance with the considerate and tactful approach and empathy for the senior and his family;

- providing a sufficient amount of information and professional assistance to the family in coping with a difficult life situation;

- active listening and providing space for seniors to express their feelings and emotions.

The ability to establish and maintain verbal contact has an important place in professional behavior of health professionals and social workers. Words have tremendous strength and power. Sensitive, judicious use of words can evoke a sense of confidence, peace of mind and often help with difficult decisions. Inappropriate, incorrect and ill-considered words can affect not only the mental state of a senior, but also influence the biopsychosocial unity of the human organism. The therapeutic conditions of the healing power of words is mutual trust. In order for communication to be successful, it is appropriate that it is proportionate to the age of the senior and his/her individual circumstances. It is necessary to pay attention to simplicity, clarity, and appropriate timing.

„In daily care for serniors, we must not neglect active listening and non-directive empathic conversation as special skills that health professionals must learn during their practice." (5)

If we want communication between professionals and seniors to be effective and deliver what we expect from it, we need to look at a number of elements that contribute to it being successful. These are, for example: speed and volume of speech; length of speech; pauses; pitch of the voice. (4)

Communication with seniors also includes paralinguistic elements which form a transition from a non-verbal to a verbal method of providing information. It's not what we say; it's how we say it. In normal practice, we also use non-verbal expressions which can be defined as body language. In daily care for seniors we can take advantage of some non-verbal expressions and skills and infer from them the situation in which the senior is in. They are:

- mimic - facial expressions that communicate emotions and social satisfaction;

- proxemics - moving in or moving out of a person's personal space and frequent disruption by health professionals; 
- haptics - tactile communication and social interaction associated with hand contact and communication through touch;

- posturology - communication expressed by posture, position, alignment;

- gestures, posturics and kinesics - expression through physical activities used to frequently express feelings;

- views - signal not only current emotions, but are a means of regulating the relationship.

Communication with each senior is a twoway process involving both listening to them and accepting their message, as well as providing the necessary information to meet the needs of the senior. In daily practice, we must not forget the reality to whether the client does not suffer from any sensory disorders or reduced cognitive functions. Polymorbidity and especially dementia syndrome play a role. We cannot forget: the age; education; influence of the environment; peace; privacy; interest and willingness of the senior to communicate; interest and willingness of the health care provider to communicate; their abilities and knowledge of communication skills and methods of establishing a relationship; use of emotional intelligence.

Communication with seniors also has its specifics:

- the elderly person reacts more slowly in communication - meaning, for example, communication problems with members of the younger generation who tend to be less patient;

- memory disorders affect the communication of seniors in that one cannot recall certain situations, numbers, names, etc.;

- repetition of what has already been said, when the senior needs to make sure that the listener understands what they wanted to say; it can also be a feeling of insecurity or reduced concentration;

- due to hearing problems, seniors put considerable effort into communication, and despite great efforts they may not understand the information and react disproportionately to the situation;

- the tendency of seniors to communicate with others through physical difficulties is very common (they often and happily discuss illnesses and difficulties in order to draw attention to themselves);

- a big problem for seniors is communication in a larger group of people where any potential noise and background noise complicates the seniors' hearing who may not be able to perceive everything, which leads to fear of repeated questioning and therefore prefers to withdraw into passivity.

Communication with seniors represents a challenge for health and social workers regarding their communication skills. In general, the factors ,I want, I know“ are applied in communication both on the part of the professional and the senior. I want on the professional side means that he will be active in the conversation, will actively listen and will use the information obtained for the benefit of the user. I want on the senior's side is influenced by the environment in which the senior is located (home environment, medical - social facilities). With regard to the environment they usually communicate openly with a certain mistrust and concern about how the information will be handled. There is taboo in the area of intimacy and sexuality. Willingness to communicate also decreases when people: suffer from pain; health complications; fatigue; anxiety; fear. I know on the professional side means that it is not sufficient with normal communication skills. The complexity of situations requires a certain superstructure which must be learned. I know on the senior's side means being able to speak naturally. The possibility and ability to communicate is more problematic on the part of the senior. In order to receive and process information, one must be able to perceive and store information in memory. Deteriorating hearing, vision, environmental orientation, time, and many other factors can be obstacles.

Social communication with an elderly person is not simple as it requires not only patience but also sufficient professional competence and quality preparation. Quality communication is a key element of good clinical practice and an integral part of the competence of health professionals and social workers in their daily activities.

\section{Conclusion}

Changing the approach to communication is a very challenging task, especially for the senior population. It is necessary to think about how to improve the communication process itself. When working with seniors in the field of ethical approach and psychosocial work, we should be fo- 
cussed not only on the new paradigms corresponding to the society of the 21 st century, but also on the European Charter of the Rights of Patients for the Elderly. Only quality and successful communication will become the key to satisfying their needs.

\section{References:}

1. KALVACH Z, ONDERKOVA A (2012) The concept of gerontological patient and their problems in nursing practice Prague: Galen ISBN 80-7262-455-5.

2. KUTNOHORSKA J (2007) Ethics in nursing Prague: Grada ISBN 978-80-247-2069-2.
3. PTACEK R et al. (2011) Ethics and communication in medicine Prague: Grada ISBN 97880-247-3976-2.

4. TKACOVA M, TARHAJ R (2015) Together for a better life. In: Health and Social Work. ISSN 13336-9326. Vol. 10, no. 1, p. 47-54.

5. VENGLAROVA M (2006) Communication for nurses Prague: Grada, ISBN 80-247-12628.

6. GUTH A (2019) Pain - friend or foe. In: Rehabilitation. Vol 56, No 4, 2019, ISSN 03750922, p. 2-3.

7. VYMETAL J (2009) Medical psychology. Prague: Portal, 2009. ISBN 80-7178-740-x. 